\title{
RADIOMETRIC MEASUREMENTS ON THE CARBON ARC AND OTHER LIGHT SOURCES USED IN PHOTO- THERAPY
}

\author{
By W. W. Coblentz, M. J. Dorcas, and C. W. Hughes
}

ABSTRACT

In the present paper lata are given on the distribution of energy in the spectrum of the carbon arc under various conditions of operation. The problem was attacked by two methods: (1) The energy distribution in the visible and in the ultra-violet spectrum of the radiation emitted from the central line through the arc and incandescent electrodes was obtained by means of a quartz spectroladiometer, and (2) by means of transmission screens the spectral radiation components of the whole arc, including the surrounding reflector, if present, were obtained in seven steps throughout the complete spectrum.

Data are presented on the variation in the radiation from the carbon arc, using different sizes and kinds of carbon electrodes, different kinds of cores, and the effect of a. c. and d. c.

Comparative data are given on the sun, the gas-filled tungsten lamp, the quяrtz mercury arc, and the arc between metal rods of tungsten and of nickel. The results obtained show that while the carbon arc approaches nearest the sun in spectral energy distribution it is important to use the proper size of electrode and current in order to obtain the most efficient operation of the lamp.

The high intensity arc was studied, and while it was found useful for large installations the same relative proportions of ultra-violet to the total emitted can be obtained from a small unit utilizing 20 to 30 amperes as is obtained from the larger unit taking 90 to 125 amperes.

\section{CONTENTS}

II. Apparatus and methods ___ 536

1. Radiometric equipment__. 336

2. Lamp equipment____ 540

3. The carbon electrodes used

III. Comparative data____. 541

1. The sun

2. The gas-filled tungsten lamp 545

3. The quartz mercury arc

4. The nickel and tungsten ares___- 546

5. The carbon arc. 547

IV. Spectral energy measurements on the carbon arc

1. Effect of the core

2. Effect of the current

3. Direct rersus alternating current_____________ 552

4. Effect of combinations of neutral core and impregnated carbons_-_-_-_-_- 552

5. High intensity ares

6. Concluding remarks___ 556

Y. Summary 


\section{INTRODUCTION}

In view of the interest of the subject to phototherapists, in a previous paper data were presented on the ultra-violet component radiation from the carbon and the mercury arc lamps and from the sun. The data thus summarized ${ }^{1}$ for the benefit of phototherapists foreshadowed further investigation in this domain.

The present investigation was carried out in cooperation with the research laboratory of the National Carbon Co., who provided extensive lamp equipment and a part of the personnel.

In Table 1 is given a summary of the various samples of material examined and the number of the illustration in which the spectral energy curve is depicted.

TABLE 1.-Summary of matcrial examined and the number of the illustration in which the spectral energy curve is depicted

\begin{tabular}{|c|c|c|c|}
\hline & Figures & & Figures \\
\hline$y^{2}$ & \multirow{14}{*}{$\begin{array}{r}6 \\
10,15,16 \\
3,14 \\
3 \\
4 \\
20 \\
8 \\
8 \\
19 \\
20 \\
3 \\
17 \\
2 \\
9,14,15,16 \\
19 \\
20 \\
2 \\
5 \\
19\end{array}$} & \multirow{14}{*}{ 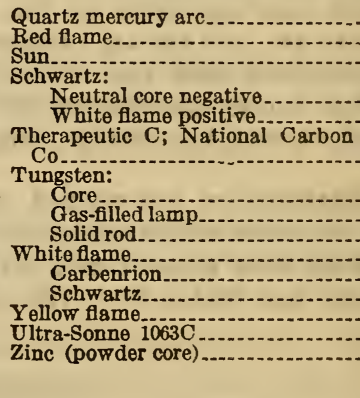 } & \multirow{14}{*}{$\begin{array}{r}2 \\
13,16 \\
18 \\
11 \\
7 \\
7 \\
8,9 \\
11,16,17,20,21 \\
20 \\
18 \\
12,16 \\
19 \\
7\end{array}$} \\
\hline $\mathrm{s}$ & & & \\
\hline & & & \\
\hline & & & \\
\hline & & & \\
\hline & & & \\
\hline & & & \\
\hline H & & & \\
\hline & & & \\
\hline & & & \\
\hline $\begin{array}{l}\text { ckel: } \\
\text { ckel }\end{array}$ & & & \\
\hline $\begin{array}{l}\text { S. \& F } \\
\text { Solid }\end{array}$ & & & \\
\hline & & & \\
\hline & & & \\
\hline
\end{tabular}

\section{APPARATUS AND METHODS}

Under the present caption are given some of the essential details of the experimental procedure and the apparatus used in this investigation in which the measurements were made in duplicate (1) by mapping the ultra-violet spectrum by means of a quartz spectroradiometer and (2) by measuring the spectral components of the total radiation emitted by the arc, by using a thermopile and screens which completely absorb certain spectral regions and freely transmit other parts of the spectrum. ${ }^{2}$

\section{RADIOMETRIC EQUIPMENT}

The radiometric outfit consisted of an ironclad Thompson galvanometer ${ }^{3}$ and a portable vacuum thermopile of bismuth and silver. ${ }^{*}$

1 Coblentz, Am. J. Electrotherapeutics and Radiology, 63, p. $455 ; 1925$.

a Bureau of Standards Scientific Papers cited are obtainable only from the Superintendent of Documents, Government Printing Office, Washington, D. C.

${ }^{3}$ Coblentz, B. S. Sci. Papers (No. 282), 13, p. $423 ; 1916$.

t Coblentz, B. S. Sci. Papers (No. 413), 17, p. 187; 1221. 
The distribution of energy in the ultra-violet and in the visible spectrum was determined by means of a spectropyrheliometer, having a quartz prism, and plano-convex lenses $6 \mathrm{~cm}$ in diameter and $20 \mathrm{~cm}$ focal length. ${ }^{5}$ In order to eliminate the effect of scattered radiation, a shutter of window glass was used in making the measurements of wave lengths less than $300 \mathrm{~m} \mu$, a red glass for the spectral region from 300 to $590 \mathrm{~m} \mu$, and an aluminum shutter for wave lengths greater than $590 \mathrm{~m} \mu$.

In this apparatus the spectrometer arms are fixed and the thermopile is moved through the spectrum. For this purpose the thermopile mounting is provided with two screws and graduated scales, one for displacing the exit slit in the spectrum and the other for focusing. The sides of the exit slit, facing the prism, are covered with white paper which is painted with a fluorescent material; ${ }^{6}$ for example, anthracene dissolved in benzol. By this means one can view the ultra-violet spectrum by the fiuorescence produced and determine at once the ultra-violet emission of the material in the arc.

The spectrometer slit was $1 \mathrm{~mm}$ in width, which was sufficient to resolve the wide bands (but not the fine lines) and provided sufficient intensity in order to make it possible to measure the extreme ultraviolet in the carbon arc on low currents. The observed galvanometer deflections are reduced from prismatic to normal spectrum by correcting for slit width, just as though the spectrum were continuous. In the illustrations the ordinates marked "Galv. Defl." are not the observed deflections but the reduced values which are proportional to the relative energy in the normal spectrum.

In the spectroradiometer the image of the arc is focused on the spectrometer slit. Hence, the spectral energy distribution is obtained over only a small portion of the arc, whereas in phototherapy the subject is exposed to the total radiation from the arc, including oftentimes a reflector or hood which becomes heated. While this low-temperature radiation probably has but little therapeutic value, it is desirable to determine the amount present. For this purpose we have employed the second method, using absorption screens.

In previous researches the effect of this low-temperature radiation was eliminated from the measurements by placing in front of the thermopile a cell of water $1 \mathrm{~cm}$ in thickness and having windows of quartz. Similarly, in the second method of the present investigation, we give the spectral components obtained by using the water cell in place, which limits the total radiation to wave lengths up to $1,400 \mathrm{~m} \mu$ (millimicrons; $\mu=0.001 \mathrm{~mm}$ ). However, since some experi-

5 Coblentz and Kahler, B. S. Sci. Papers (No. 378), 16, p. 283; 1920.

' Coblentz, Methods and apparatus in spectroradiometary, J. Opt. Soc. Am., 7, p. 451; 1923. 
menters have made comparisons using the total radiation, without the water cell as a limiting screen, we have made the comparisons of the spectral components also in per cent of the total radiation of all wave lengths to $12,000 \mathrm{~m} \mu$, which is the limit of transparency of the fluorite window of the thermopile. The method of transmission screens gives an integration of wide spectral regions and gives an analysis of the radiation emanating from the whole lamp, including reflector and other surroundings.

The use of screens, including red glass and quartz, for isolating different portions of the spectrum, was described in previous papers. ${ }^{7}$ After determining the spectral transmission of various samples. the most suitable screens were selected for this investigation. Some of the screens were used in the germicidal investigations. ${ }^{8}$ The transmission curves are given in Figure 1. From this it is evident

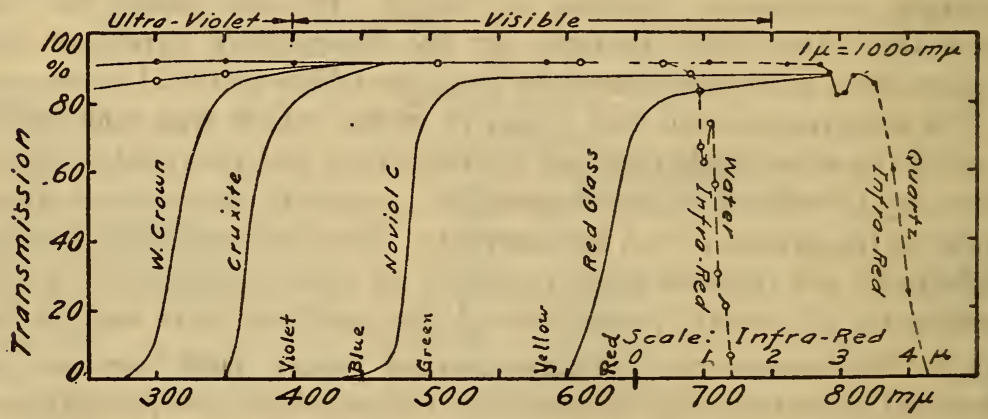

Frg. 1.-Showing the spectral regions transmitted and absorbed by the various screens

that by inserting the proper screen or combination of screens (for example, water and red glass) it is possible to obtain some knowledge of the component radiation in the spectral ranges of 170 to $290 \mathrm{~m} \mu$, 290 to $350 \mathrm{~m} \mu, 350$ to $450 \mathrm{~m} \mu$, etc. The short wave length limit at $170 \mathrm{~m} \mu$ is determined by the opacity of the atmosphere. The use of the Cruxite glass is new. It was included to isolate and obtain a measurement of the intensity of the cyanogen band at $389 \mathrm{~m} \mu$, which varies greatly with the current and with the kind of material forming the core of the carbon. By taking from 10 to 40 readings with each screen in place, and by frequently interchanging the screens, a fairly accurate estimate was obtained of the various spectral components. Owing to the great fluctuations in temperature, and hence of the ultra-violet radiation at 170 to $290 \mathrm{~m} \mu$ and from 290 to 350 $\mathrm{m} \mu$, which is only a small part of the total spectrum, the errors of

${ }^{7}$ Coblentz, B. S. Sci. Papers (No. 438), 17, p. 725 ; 1922.

8 Coblentz and Fulton, B. S. Sci. Papers (No. 495), 19, p. $641 ; 1924$. 
observation in the ultra-violet are necessarily larger than in other parts of the spectrum.

The spectral transmission curve of a cell of water $1 \mathrm{~cm}$ thick, illustrated in Figure 1 (the scale of infra-red wave lengths is in microns; $\mu=0.001 \mathrm{~mm}$ ), is interesting in showing that but little radiation of wave lengths greater than $1,400 \mathrm{~m} \mu$ can penerate deeply into the human body. In a previous research ${ }^{9}$ it was shown that a layer of water $0.3 \mathrm{~mm}$ in thickness is opaque to radiation of wave lengths greater than $2,500 \mathrm{~m} \mu$. Numerous researches made by various investigators during the past three decades are in agreement that water and organic tissue are extremely opaque to radiation of wave lengths 3,000 to $12,000 \mathrm{~m} \mu$. Hence, low-temperature radiation from objects heated from 50 to $100^{\circ} \mathrm{C}$. can not penetrate the skin deeper than a few hundredths of a millimeter. If, therefore, such a low-temperature heater has any therapeutic efficacy, it is probably to be attributed to thermal conduction to the interior.

Before the spectral components could be calculated the observations obtained with the various screens had to be corrected for reflection and absorption. These corrections were as follows: For the quartz and the water cells, used singly, the correction by reflection for each was 1.09; for the water cell combined with the white-crown glass screen (No. 4 in B. S. Sci. Paper No. 495), the Cruxite glass, the Noviol C, and the red glass the correction factors were, respectively, 1.17, 1.17, 1.26, and 1.18; there being a slight correction for absorption as well as reflection in the Noviol and red glasses. From measurements on a gas-filled tungsten lamp the correction factors for the No. 4 and the Cruxite glass seem quite accurate; but there is some uncertainty regarding the red glass, though this is relatively unimportant, since all the data are comparative and obtained with the same apparatus.

By means of a standard of radiation ${ }^{10}$ this thermopile, without the transmission screens, was calibrated to read energy units. In this manner the total radiant flux in watts per $\mathrm{cm}^{2}$ at a distance of $1 \mathrm{~m}$ from the center of the arc was obtained from each lamp (see Table 2). If it is desired to reduce these data to calories per minute, they should be multiplied by the factor $(60 \div 4.18=)$ 14.35 .

The illumination produced by the various ares was determined by means of a Macbeth illuminometer calibrated by the photometry section of the bureau. This instrument should prove to be a ready means for measuring the (visual) illumination, and hence the irradiation dosage for each type of carbon arc. For this purpose screens should be provided for color matching each type of arc with the comparison lamp.

${ }^{9}$ Coblentz, B. S. Bull. (No. 168), 7, p. 631; 1911.

${ }^{10}$ Coblentz, B. S. Bull (No. 227), 11, p. $87 ; 1914$. 
Owing to the high candlepower of the motion-picture projector ("high intensity") arc it was most convenient to use our thermopile as a physical photometer. For this purpose a luminosity solution, having a transmission curve of the average eye, ${ }^{11}$ was placed in front of the thermopile and the galvanometer deflection noted when exposed to a standard of radiation of known candlepower.

\section{LAMP EQUIPMENT}

A variety of arc lamps was at our disposal. The isochromatic radiation data were obtained with a vertical-trim, hand-operated arc lamp, with ordinary laboratory resistance for ballast, enabling us to obtain currents from 5 to 30 amperes. Similarly, a right-angled trim, hand-operated arc lamp was used.

The vertical-trim carbon arcs, requiring 30 to 60 amperes, were operated in a new type tilting lamp with electrically controlled arc, which is surrounded with a reflector. This lamp is made by the Macbeth Arc Lamp Co., Philadelphia, Pa.

Data were obtained on one or two vertical-trim arcs, on 10 to 20 amperes, operated in a Perkins portable trim-arc lamp, with gravity control, made by the Photogenic Machine Co., Youngstown, Ohio. This lamp uses two arcs in series, on 110 volts, in a rectangular inclosure. The spectral energy curves were obtained on a single arc. Total and spectral component radiation measurements were made on the single, and also on the two arcs. When the pair of arcs were used, the distance $(1 \mathrm{~m})$ was measured from the center line between the two arcs.

The data on the high intensity arc ("H. I. white flame") on 90 and 122 amperes were obtained with a General Electric Co. motion-picture projector lamp. This is an inclined-trim arc, in which the (upper) horizontal, positive carbon is rotated and the length of the arc is controlled electrically while in operation.

The Schwartz therapeutic lamp in its present form consists of a straight-trim arc of a copper-covered, "oro-tip," neutral-core (upper) negative, and a white-flame (lower) positive, carbon electrode, backed with a white diffusing reflector. The lamp was operated on 90 amperes. Under these conditions the spectral intensities were five times those observed on a 29 -ampere white-flame arc in the Macbeth lamp. However, owing to the type of reflector in the latter, the total radiation intensity, at a distance of $1 \mathrm{~m}$, differed but little in these two types of lamps.

\section{THE CARBON ELECTRODES USED}

In order to obtain a quiet burning arc, the electrode is made of an outer hard shell of compact carbon with a core of soft carbon flour 
and a small amount of potassium silicate or other arc-supporting material. This is known as the "neutral-core" carbon or "dochtkohle." By using salts of various metals, or the finely powdered metal, mixed with carbon flour, as a core, or the metal wire inserted in the boring through the hard carbon shell, the various impregnated carbons are obtained. Trade names do not conceal much of the contents of the electrode from the investigator provided with a spectroscope, though it may be a badge of a method of preparation.

The "white-flame" and "carbenrion" carbons contain, among other things, the fluorides of the rare earths remaining after the removal of the thorium from monazite sand.

The "blue-flame" carbons contain iron which is known to have an emission spectrum of many lines, especially in the ultra-violet.

The "yellow-flame" carbons contain calcium, and the "red-flame" carbons are strongly impregnated with strontium salts.

The "effekt-ultra," the "ultra-sonne," and the "nickel-cored," carbons give the same emission spectrum, namely, that of nickel, which has a strong ultra-violet emission in the region of 220 to 350 m $\mu$. Some of our samples of nickel-cored carbons contained wires 1.5 $\mathrm{mm}$ in diameter.

The "copper-cored" carbons were made of the finely powdered material. The "zinc-cored" electrodes contained the powdered material. Other samples with a "white-flame" material in the core contained also a zinc wire; but this did not seem to have a marked effect on the radiation emitted. The "aluminum-cored" carbons were first tried out by inserting a 1.5-mm wire in holes bored in graphite electrodes. Subsequently, aluminum wires 1.5 and $2 \mathrm{~mm}$ diameter, also the powdered material, were placed in the regular carbon shells in the factory. The $1.5-\mathrm{mm}$ wire seemed better than the powdered material; the thicker wires seemed to produce an unsteady arc as a result of oxidation. This should prove to be an excellent source of isolated intense emission lines useful to spectroscopists interested in ultra-violet absorption spectra.

The "cobalt-cored" arc contained the powdered metal. The are burned smoothly, emitting a strong ultra-violet radiation. The high intensity ("H. I.") white-flame carbons, 11 and $13.6 \mathrm{~mm}$ in diameter, contained a "hard-p.n" core.

\section{COMPARATIVE DATA}

In view of the numerous inquiries for data on the sun and other sources of radiation, it is relevant to include some information of this type in the present investigation. However, as pointed out in previous papers, there can be no exact comparison of the radiometric

$10715^{\circ}-26-2$ 
measurements or of the therapeutic effects produced by the ultraviolet and the luminous rays from these three sources, because they are at different temperatures and have different spectral radiation components.

In this paper the wave lengths are in millimicrons $(m \mu)$, the ultraviolet being the region from wave lengths 170 to $400 \mathrm{~m} \mu$ or 1,700 to 4,000 A. U.

\section{r. THE SUN}

In Figure 18 is given the spectral energy distribution of the sun for average atmospheric transmission at sea level (Washington, D. C., altitude 35 feet) and at a high altitude (Mount Wilson, altitude 5,665 feet). The data were taken from the Smithsonian Physical Tables, seventh revised edition, for air mass 1 -that is, at noon near summer solstice. The intensities are much lower in the ultraviolet for large air masses $(\mathrm{m}=2$ to 3$)$-that is, at noon during winter solstice and for a low sun in summer.

The temperature of the effective radiating layer in the sun is up to $6,000^{\circ} \mathrm{C}$., as measured at sea level. The intensity of the shortest ultra-violet solar rays transmitted at our atmosphere is extremely small. Fabry ${ }^{12}$ found that at sea level the intensity at $290 \mathrm{~m} \mu$ is only one-millionth as great as at $3.5 \mathrm{~m} \mu$ (where the mercury arc has a strong emission line) and only one forty-millionth of the maximum solar intensity which is in the visible spectrum. Owing to absorption by the earth's atmosphere at sea level, no radiation of wave lengths shorter than about $290 \mathrm{~m} \mu$ reaches the earth. Similarly, owing to the opacity of the earth's atmosphere, but little infrared radiation of wave lengths longer than $3,000 \mathrm{~m} \mu$ is received from the sun. As shown in Table 2, less than 1 per cent of the total solar radiation reaching the earth's surface is of wave lengths longer than $4,000 \mathrm{~m} \mu$. This is an important fact to remember in making comparisons with therapeutic lamps emitting a great deal of low-temperature radiation from the hood, surrounding chimney, etc.

Comparative data of the spectral component radiation of the sun and of other sources are given in Table 2. It is interesting to note the marked increase in the ultra-violet component with altitude. The value for the spectral range 170 to $450 \mathrm{~m}_{\mu}$ is less than $0.13 \mathrm{~g}$ calorie (for air mass 1 ) at Washington, as compared with $0.25 \mathrm{~g}$ calorie at Flagstaff, Ariz., which is at an altitude of 7,000 feet. The solar radiation intensity falling on a surface normal to the incident rays, at Washington, at the noon hour on a clear day amounts to about $1 \mathrm{~g}$ calorie per $/ \mathrm{cm}^{2}$ per minute and rarely rises to $1.2 \mathrm{~g}$ calorie as compared with $1.6 \mathrm{~g}$ calorie at Flagstaff.

12 Fabry, Astrophys. J., 54, p. 297, 1921. 


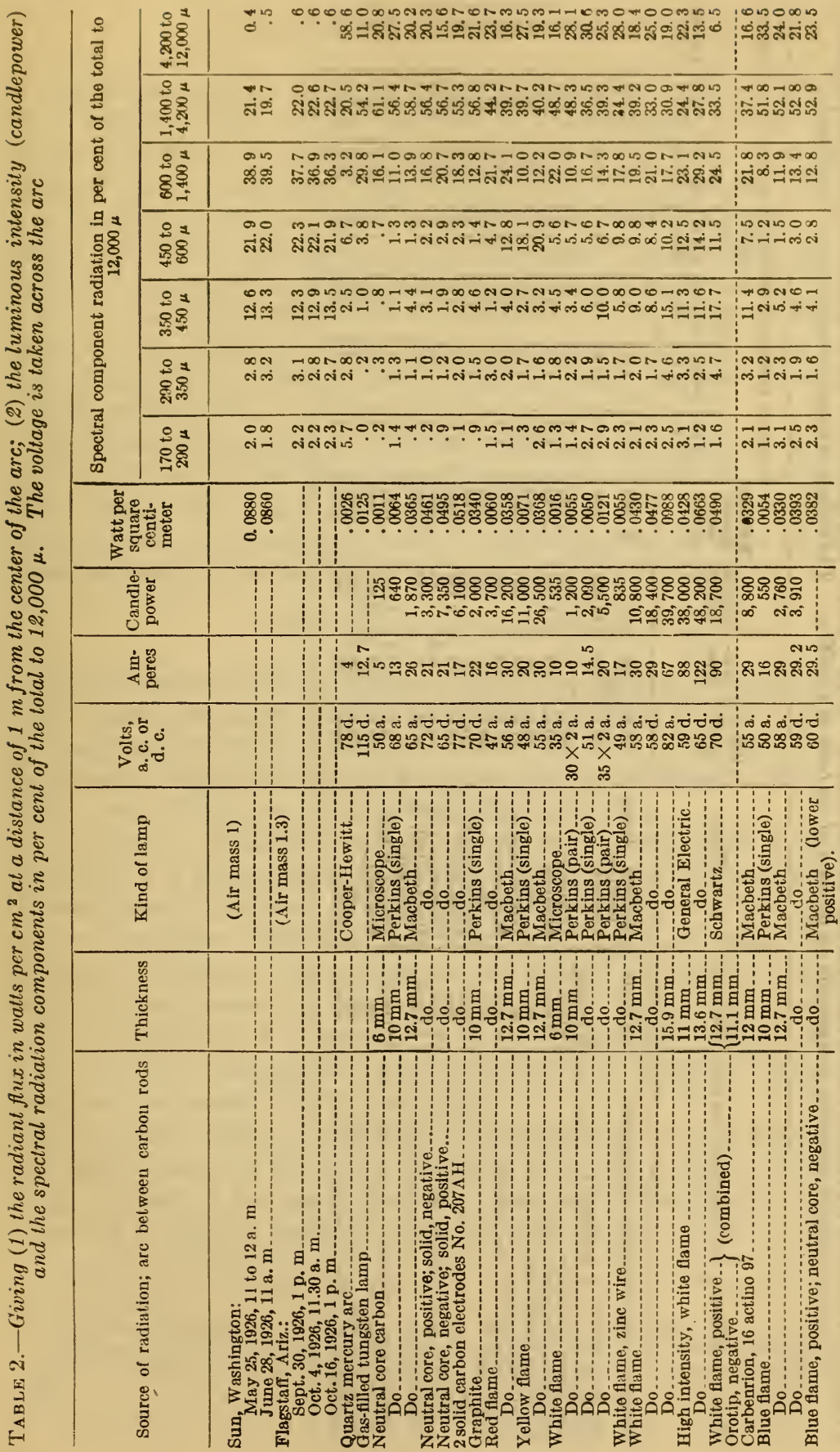




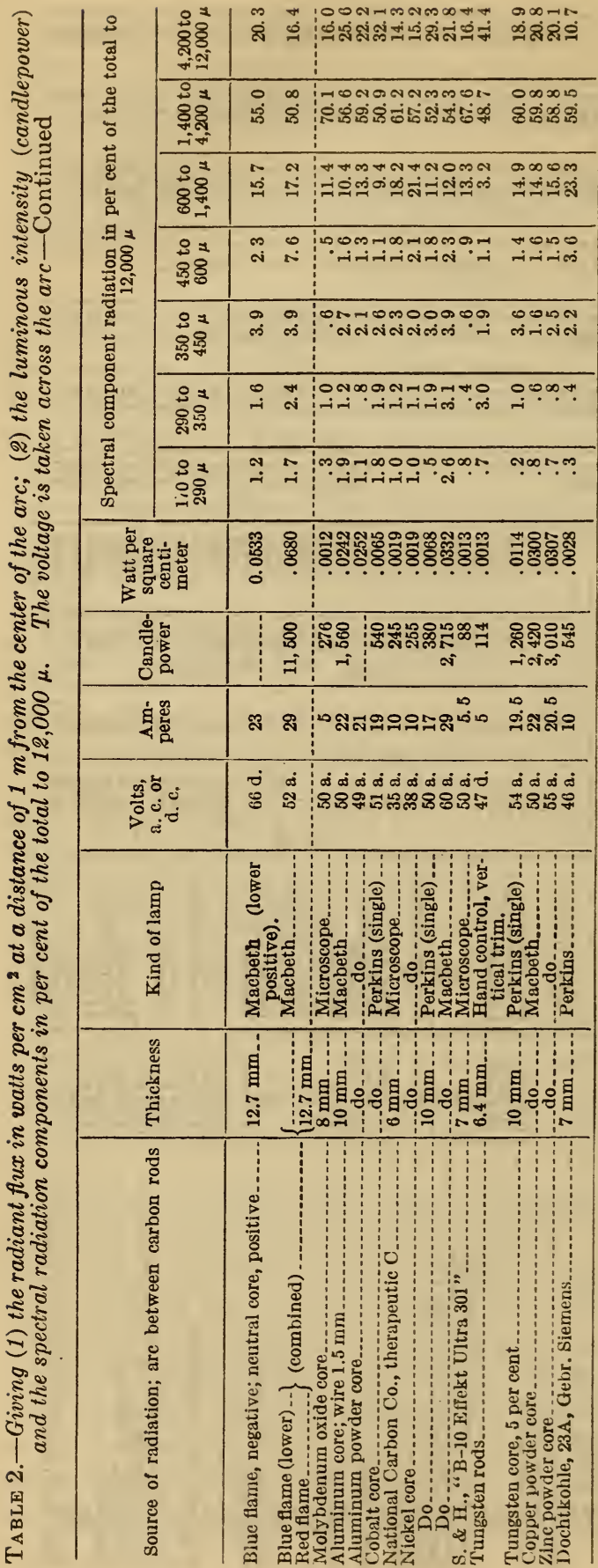




\section{THE GAS-FILLED TUNGSTEN LAMP}

Measurements were made on a 1,500-watt gas-filled tungsten lamp, but without a reflector such as used in a therapeutic lamp. The reflector would increase the total intensity in the direction observerl. The ultra-violet radiation emitted from the gas-filled tungsten lamp is extremely small (sce Table 2). The visible radiation is only 3 to 4 per cent of the total emitted. The bulb, which was of clear glass, absorbs practically all of the radiation of wave lengths longer than 3,000 $\mathrm{m} \mu$, and it absorbs completely all the radiation of wave lengths greater than $4,500 \mathrm{~m} \mu$. The low-temperature radiation from the heated glass bulb (some 11 per cent of the total) can not penetrate deeply into the skin.

The spectral-component radiation extending from $600 \mathrm{~m} \mu$ in the red to $1,400 \mathrm{~m} \mu$, amounting to about 30 per cent of the total, can penetrate deeply into the skin, and hence can be effective therapeutically. Readers are referred to the original papers for data on the spectral-energy distribution of the gas-filled tungsten lamp..$^{13}$

\section{THE QUARTZ MERCURY ARC}

The radiation from the quartz mercury arc lamp is distributed in a few intense emission lines, as illustrated in Figure 2. From Table 2 it may be noted that about 6 per cent of the total radiation emitted is of wave lengths shorter than $290 \mathrm{~m} \mu$, which are absent from the solar rays. They have a high germicidal action. ${ }^{14}$

In previous investigations ${ }^{15}$ of quartz vapor lamps with burners having (1) a solid tungsten anode and (2) a liquid mercury anode it was found that there is no appreciable difference in the ultraviolet component radiation from these two types of lamps when operated on the same energy input in the burner. Air-cooled burners operated on alternating current (through the burner) and watercooled burners on d. c. appear to have a somewhat higher ultraviolet radiation component than air-cooled d. c. burners, owing to the lower temperature of the inclosure.

Aside from several strong lines in the region of 1,000 to $1,200 \mathrm{~m} \mu$, the quartz mercury arc emits but little infra-red radiation. ${ }^{16}$ The large amount of infra-red obtained from the Cooper-Hewitt lamp, recorded in Table 2, emanates from the incandescent tungsten anode,

\footnotetext{
12 Coblentz, B. S. Sci. Papers (No. 300), 14, p. 115, 1917 ; B. S. Sci. Papers (No. 443), I\&, p. 225, 1922.

${ }^{14}$ Coblentz and Fulton, B. S. Sci. Papers (No. 495), 10, p. 641, 1924.

${ }_{15}$ Coblentz, Long, and Kahler, B. S. Bull. (No. 330), 15, p. 1, 1918; Coblentz and Kahler, B. S. Bull. (No. 378), 16, p. 233, 1920 ; Coblentz, Am. J. Radiology, 39, p. 395, 1921.

${ }^{26}$ Cublentz, B. S. Bull. (No. 191), 9, p. $96 ; 1912$.
} 
and especially from the quartz inclosure, and the hood, which emit a low-temperature, long-wave length radiation that can not penetrate deeply into the skin. In this respect there is no comparison between this type of radiation and that of the sun, and it is hardly to be expected that these two sources will gire the same results in all types of light treatment and in dye fading.

In concluding this discussion of the emissive properties of quartz mercury lamps it is relevant to mention some recent observations on the change in efficiency with age. In our investigations made eight years ago the lamps showed some deterioration with usage. As mentioned elsewhere, ${ }^{17}$ since then marked improvements have been made in the construction of quartz mercury lamps, which no longer show the rapid discoloration with usage previously noted. For

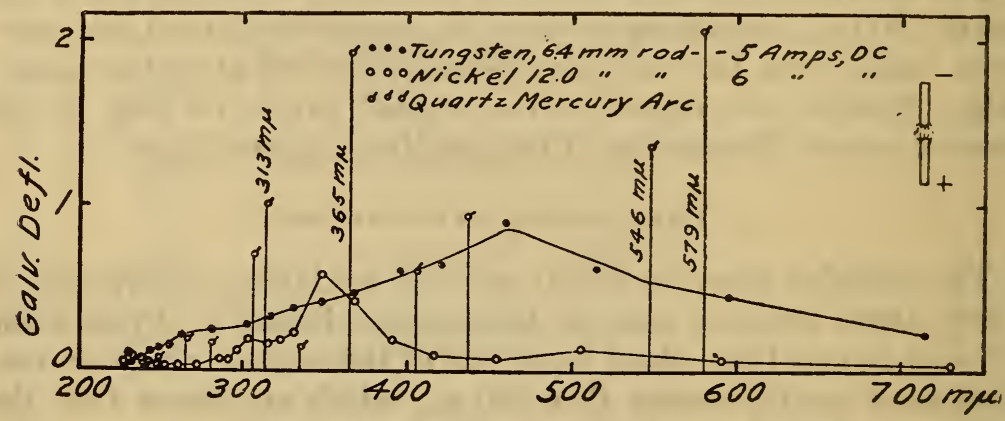

FIG. 2.-Emission spectrum of arc between metal electrodes

example, the measurements cited in the present paper were made on a quartz mercury arc burner that had been operated about 700 hours. The transmission through the shade B. Noviol glass was 37.7 per cent, as compared with 37.8 per cent observed in our germicidal work two years earlier, when the lamp was new, showing that within the errors of observation there was no appreciable decrease in the ultra-violet component radiation relative to the total during the 700-hour usage. For, if there had been an appreciable decrease in the ultra-violet emitted, then the recently observed per cent transmission through the Noviol glass should have been larger instead of smaller than the previously determined value.

\section{THE NICKEL AND THE TUNGSTEN ARC}

In contrast with the mercury arc in which the emission spectrum consists of a few intense lines, the emission spectrum of the arc between two electrodes of nickel and of tungsten consists of numerous fine lines, not resolved in our spectroradiometer (fig. 2).

${ }^{17}$ Coblentz, Am. J. Electrotherapeutics and Radiology, 39, p. $395 ; 1921$. 
The spectral energy distribution of the arc between two pure nickel rods, 12 millimeters in diameter with tapered ends, operated on 6 amperes, is given in Figure 2, from which it may be noted that the nickel are emits strongly at $230 \mathrm{~m} \mu$ and especially at $350 \mathrm{~m} \mu$. 'These bands are especially conspicuous in certain cored carbons, discusserl in a subsequent part of this paper. The arc of nickel-cored carbons is an excellent source of ultra-violet radiation. Moreover the material is inexpensive, quiet-burning, and easy to operate. The only other substance examined that compared favorably in these respects is cobalt and the National Carbon Co. "therapeutic C" cored carbons mentioned on a subsequent page.

The tungsten rods, 6.4 millimeters in diameter, examined were the regular imported British stock material used for therapeutic purposes. They were operated on 5 amperes. Owing to the formation of a crust of oxide around the electrode, the arc was rather unsteady and hence difficult to keep focused on the spectroradiometer slit.

On viewing the fluorescent screen it was evident that the emission spectrum of tungsten is weak in the spectral region of wave lengths shorter than $230 \mathrm{~m} \mu$. This was confirmed by the radiometric measurements, which show a gradual increase in intensity, beginning rather abruptly at about $230 \mathrm{~m} \mu$, with a maximum intensity in the region of $450 \mathrm{~m} \mu$.

Our earlier measurements on cored carbons containing, respectively, 5 and 15 per cent of tungsten by volume, of the core, were disappointing in that they differed but little from the neutral-cored carbons, which are weak in radiation in the ultra-violet (see figs. 4 and 8 ). The question naturally arises why physicians should use these expensive electrodes to obtain ultra-violet radiation of wave lengths less than $250 \mathrm{~m} \mu$. But as a source of radiation of wave lengths longer than $350 \mathrm{~m} \mu$, free from the intense cyanogoen band at, $389 \mathrm{~m} \mu$, the arc between rods of pure tungsten is unique.

In this connection it is relevant to recall that, in their germicidal investigations, Browning and Russ ${ }^{18}$ found that their photographs of the arc spectrum of tungsten were weak for wave lengthe less than $230 \mathrm{~m} \mu$. They found a weak germicidal action for wave lengths less than $210 \mathrm{~m} \mu$. No radiometric measurements having been made it was suggested ${ }^{19}$ that this might be owing to the weak spectral intensity of the tungsten arc. The present measurements appear to confirm this surmise.

\section{THE CARBON ARC}

The temperature of the positive electrode of the carbon arc is about $3,300^{\circ} \mathrm{C}$. The arc vapors from the electrodes of pure carbon, which

18 Browning and Russ, Archives of Radiology and Electrotheraphys, 18, p. 85; 1918.

${ }^{10}$ Coblentz and Fulton, B. S. Sci. Papers (No. 495), 19, p. 646; 1924. 
are quite nonluminous, have a strong emission in the violet. As is well known, by using cored carbons, filled with various substances, a highly luminous arc is produced.

Superposed upon the radiation from the arc vapors is the continuous spectrum from the highly incandescent crater of the positive electrode. The result is an intense infra-red spectrum, of wave lengths longer than the solar rays transmitted by the atmosphere. If we surround the arc with a glass or quartz globe, some of the infra-red rays are excluded; but in turn the surrounding globe becomes heated and emits infra-red rays. Hence, no exact comparison can be made between the radiation from the sun and the carbon arc. However, in a general way, it may be said that the radiation from the carbon are is similar to that of the sun, in that it is relatively weak in radiation of wave lengths less than $290 \mathrm{~m} \mu$. But it is strong in infra-red radiation of wave lengths greater than $3,000 \mathrm{~m} \mu$, which the earth's atmosphere has eliminated from the solar rays.

The crater of the positive electrode emits an intense white light, which, as already mentioned, is mixed with the radiation of the arc vapors. This fact is usually overlooked in discussions $\mathrm{c} f$ the radiation from the carbon arc. The vapors from the purt carbon arc contribute but a small amount to the total radiation emitted.

When the carbon arc is inclosed with a close-fitting chimney, the gases surrounding the arc expand and force sufficient air out of the chimney to establish an equilibrium in pressure; viz, atmospheric pressure. When the arc is extinguished, cold air rushes in. But this does not mean that the arc was operating under reduced pressure; that is, in a partial vacuum. The pressure was the same as, or slightly above, the atmospheric pressure, but the volume of air was reduced.

\section{SPECTRAL ENERGY MEASUREMENTS ON THE CARBON ARC}

Under this caption are given the measurements of the spectral radiation components observed with the transmission screens and also the energy distribution in the ultra-violet and in the visible spectrum $^{20}$ observed with the quartz spectroradiometer. As already mentioned, in Table 1, is given a summary of the kind of arc examined and the number of the illustration in which the spectral energy curve of a given sample is depicted.

It will, of course, be understood that, owing to the small dispersion used, the fine-line structure of the spectrum can not be

${ }^{20}$ Although the composition of high intensity carbon ares is no longer the same as used some jears ago, the energy measurements in the risible spectrum are in good agreement with the spectrophotometric measurements of Priest and his collaborators. B. S. Tech. Papers No. 168; 1920. 
determined, and it is only the maxima of the wide bands in the spectrum that are mapped in these illustrations. The fact that in some cases the ordinates have been reduced by some factor (say $\div 5$ ) does not alter the results which are comparative throughout the spectrum.

\section{r. EFFECT OF THE CORE}

As illustrated in Figures 3 and 4, and as is well known to spectroscopists, the radiation emitted by an arc of pure carbon consists principally of a wide band at about $250 \mathrm{~m} \mu$ and a more intense band,

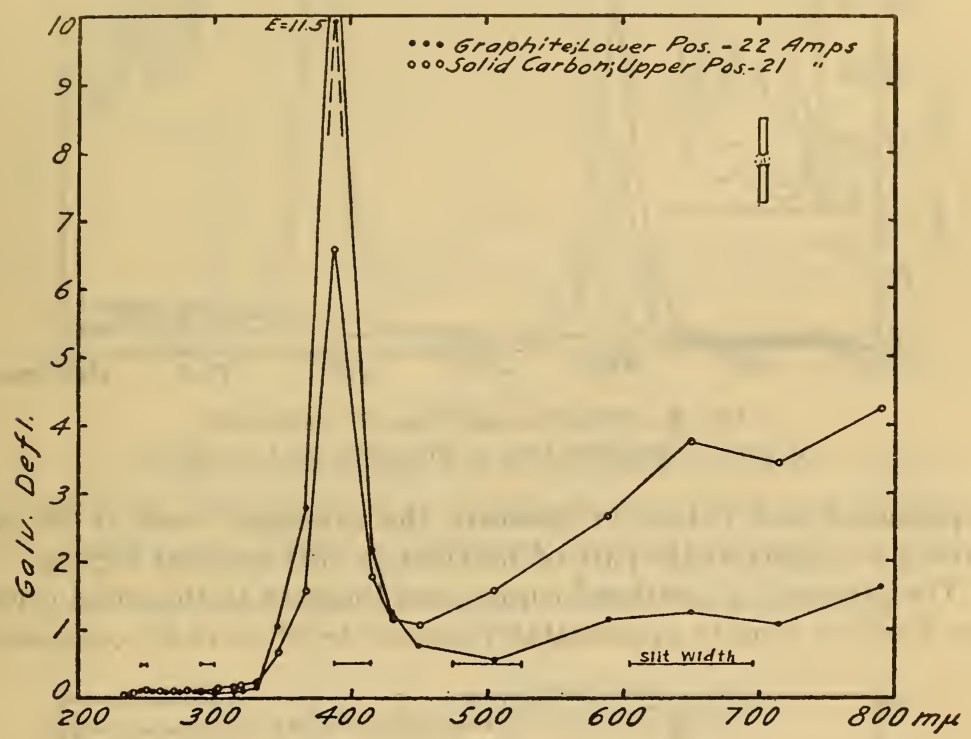

FIG. 3.-Emission spectrum of carbon arc and slit width of thermopile

"the cyanogen band," at about $389 \mathrm{~m} \mu$. The radiation in the visible spectrum, increasing in intensity toward the red, comes from the highly incandescent solid electrodes, which were intentionally focused, with the arc, upon the spectrometer slit. The intensity in this part of the spectrum depends upon the degree of incandescence of the electrodes, which are viewed to best advantage in the rightangle trimmed arc, with the horizontal electrode positive.

The effect of introducing various salts into the carbon arc is well known and is illustrated in Figure 16. In the "red flame" cored carbon (figs. 13 and 16), the effect is to suppress the cyanogen band while the strontium has a strong emission in the red end of the spectrum. 
The aluminum, cobalt, and nickel arcs (figs. 6, 8, and 5, respectively) provide a strong emission in the extreme ultra-violet, at about $230 \mathrm{~m} \mu$, supplementing the carbon band at about $250 \mathrm{~m} \mu$. The emission band of nickel at about $350 \mathrm{~m} \mu$ (figs. 2, 5, 19, 20) seems to

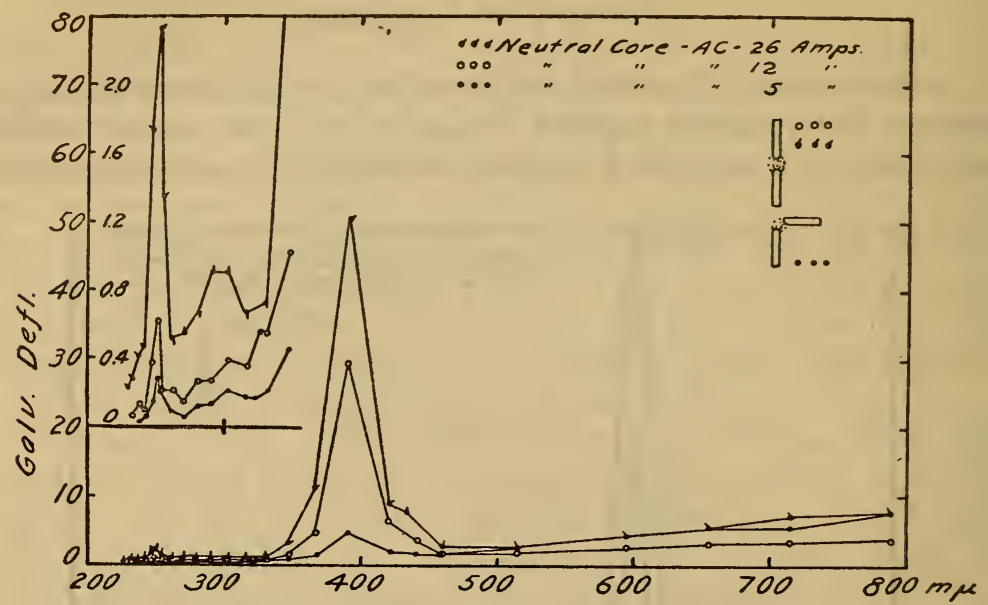

Fig. 4.-Emission spectrum of carbon arc $\Lambda t$ left is a magnified view of ultra-violet band at $250 \mathrm{~m}_{\mu}$

supplement and reduce in intensity the cyanogen band at $389 \mathrm{~m} \mu$, giving a characteristic pair of maxima in this spectral region.

The presence of powdered copper and tungsten in the cored carbon arc does not seem to appreciably increase the ultra-violet component.

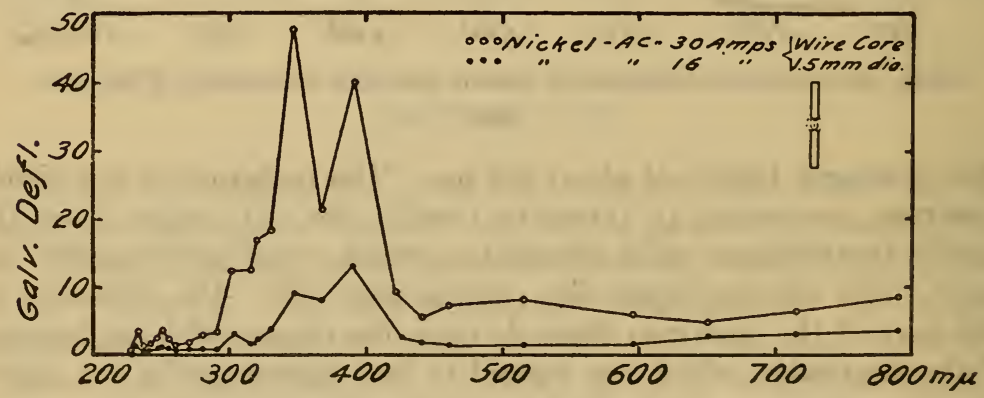

FIG. 5

This conclusion is based upon the results obtained by the two methods of measuring the ultra-violet radiation; and it is disappointing especially for tungsten, in view of the fact that the latter has been put forward for therapeutic purposes. However, considering the 
expense involved, the commoner metals, such as iron ("blue flame"), cobalt, and nickel fortunately emit the desired rays. As shown in Figure 16, the blue flame is especially rich in ultra-violet radiation of wave lengths 230 to $320 \mathrm{~m} \mu$ where all the other carbons operated on

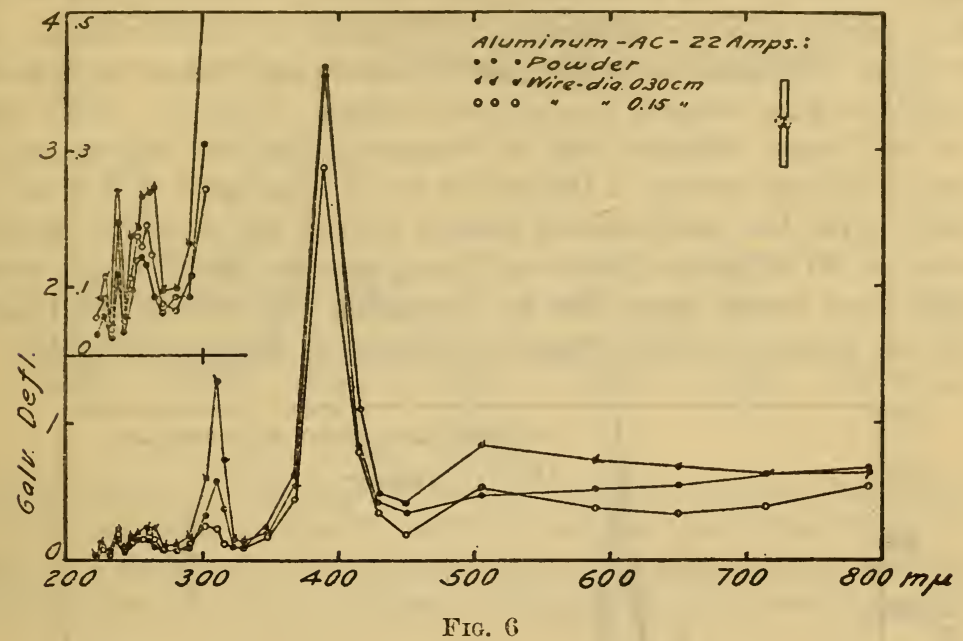

the same current are relatively much weaker in radiation intensity. It is, of course, well known that the blue flame arc has a rapid photographic action, and that it easily burns the untanned skin; but here-

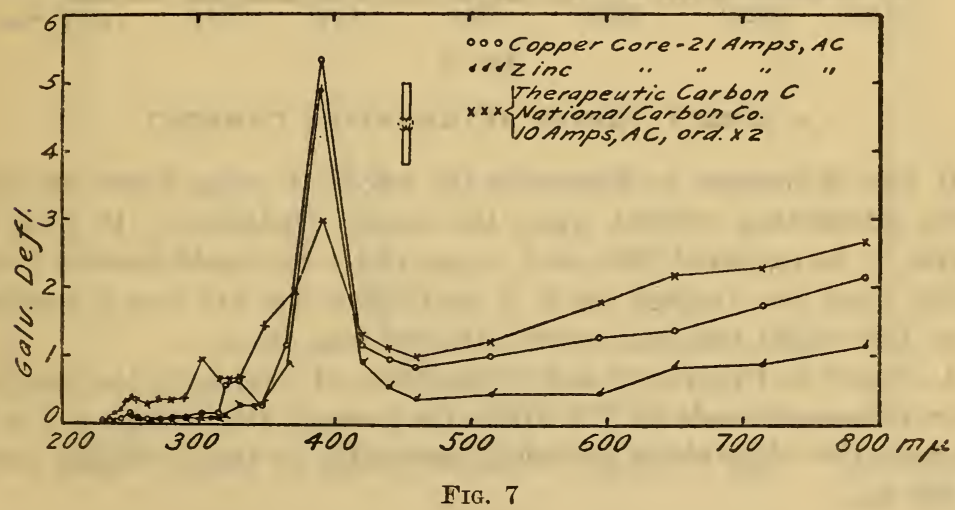

tofore no radiometric data were at hand showing the energy distribution of this remarkable are.

\section{EFFECT OF THE CURRENT}

It is well known that the strength of the electric current greatly affects the radiation emitted by the carbon arc. This is illustrated 
in Figure 4, which gives the ultra-violet spectral energy distribution of a $12.7 \mathrm{~mm}$ neutral-core carbon arc on 12 and on 26 amperes. The rapid increase in the intensity of the cyanogen band at $389 \mathrm{~m} \mu$ in changing from 5 to 26 amperes is especially noteworthy. Similar measurements on the blue-flame, yellow-flame, red-flame, and whiteflame carbon arcs are illustrated in Figures 10, 12, 13, and 17. In the latter illustration it is to be noted that on the higher currents the intensities were reduced in scale, and both a. c. and d. c. mere used.

A still more effective way of demonstrating the importance of using sufficient current in the carbon arc is illustrated in Figure 21, which gives the isochromatic energy curves for currents ranging from 5 to 30 amperes. Selecting typical emission bands in the ultraviolet these curves show that by increasing the current five to sixfold the intensity in some cases is increased as much as fiftyfold.

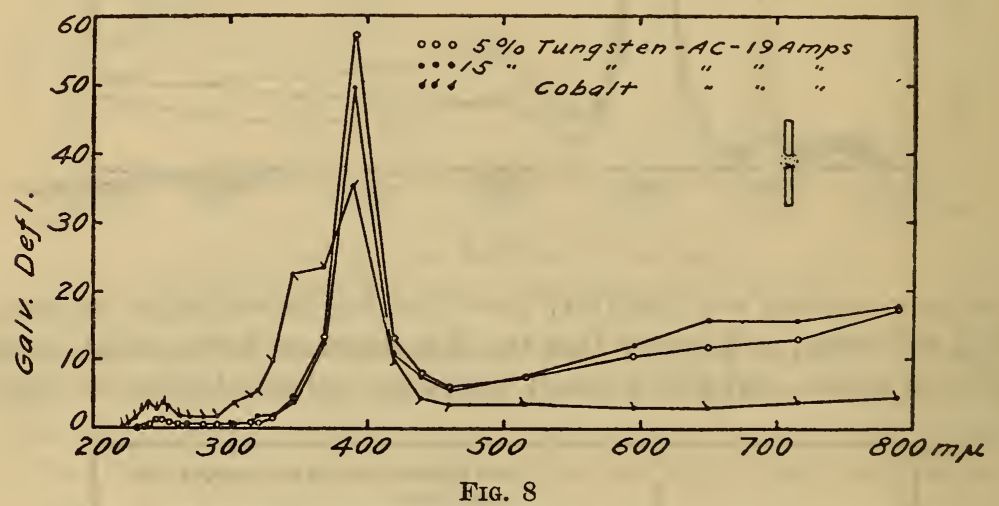

3. DIRECT VERSUS ALTERNATING CURRENT

It was of interest to determine the effect of using direct and 60 cycle alternating current upon the energy radiation. It was, of course, to be expected that on d. c. one electrode would become much hotter than the average on a. c. and, since the arc was a vertical trim, this might transmit more infra-red than on a. c.

As shown in Figures 10 and 11 the effect of increasing the temperature of one electrode on d. c. above the average attained on a. c. is to increase the ultra-violet emission, especially in the cyanogen band at $389 \mathrm{~m} \mu$.

4. EFFECT OF COMBINATIONS OF NEUTRAL CORE AND IMPREGNATED CARBONS

An examination was made of arcs in which the positive electrode was a metal-core carbon and the negative electrode was a neutral- 
core carbon, and vice versa. As shown in Figure 14, when the soft neutral core is positive the effect is to increase the intensity of the cyanogen band at $389 \mathrm{~m} \mu$. This is also demonstrated in Figure 15. Using an arc between blue-flame and neutral-core carbons, the

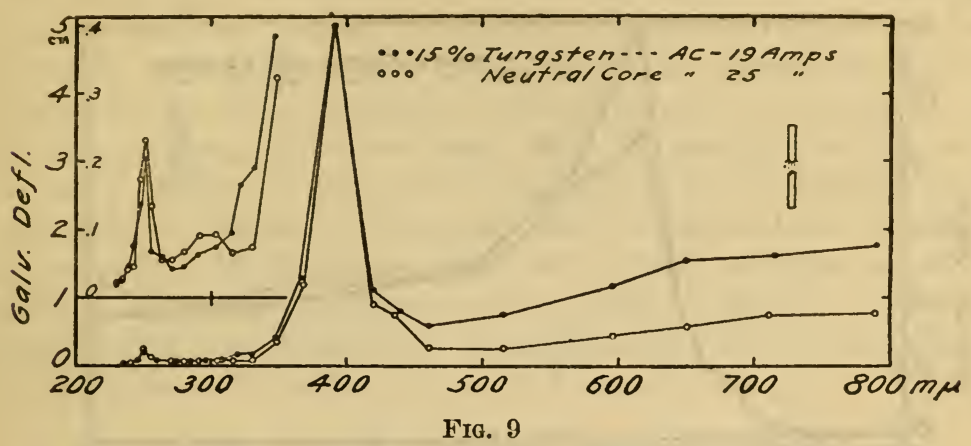

cyanogen band, at $389 \mathrm{~m} \mu$, is as intense on 22 amperes when the neutral core is positive as it is on 30 amperes when the blue-flame electrode is positive. Evidently the emission of the cyanogen band is strongest in the carbon arc, and, as shown in Figure 11, it is more intense on

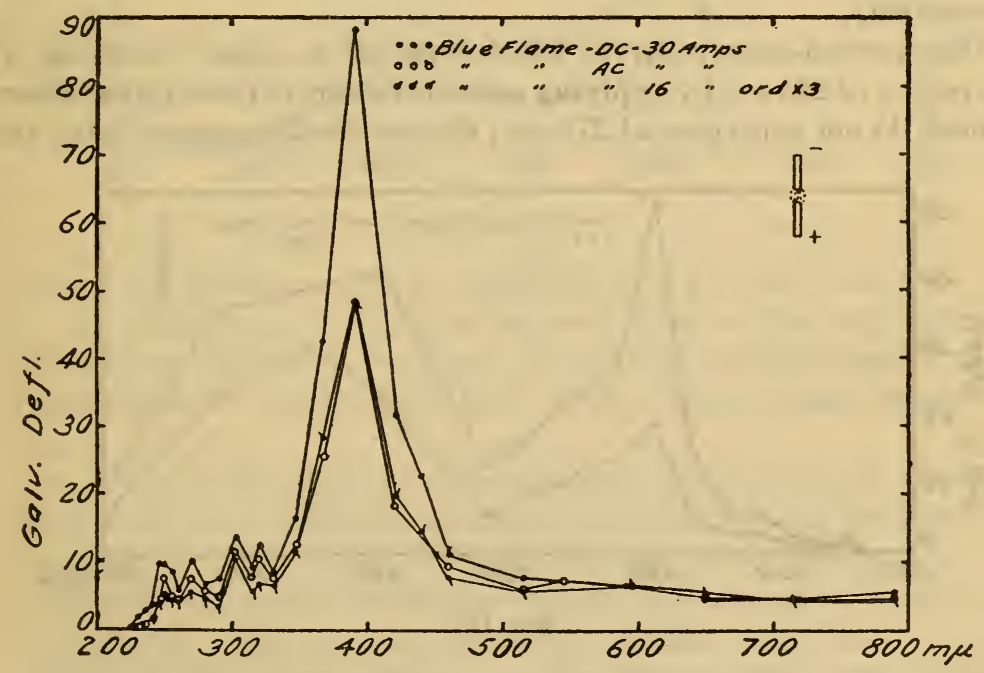

Fig. 10

d. c. than on a. c., in which the average temperature is lower and more nearly the same in the two electrodes.

\section{HIGH-INTENSITY ARCS}

For a point source of light for projection purposes the high-intrinsic brightness obtained from the 125-ampere, "high-intensity," 
white-flame arc is extremely useful. It is probably to be expected that as the current is increased more energy of shorter and shorter wave lengths will be emitted, but heretofore no direct measurements were available for the carbon arc.

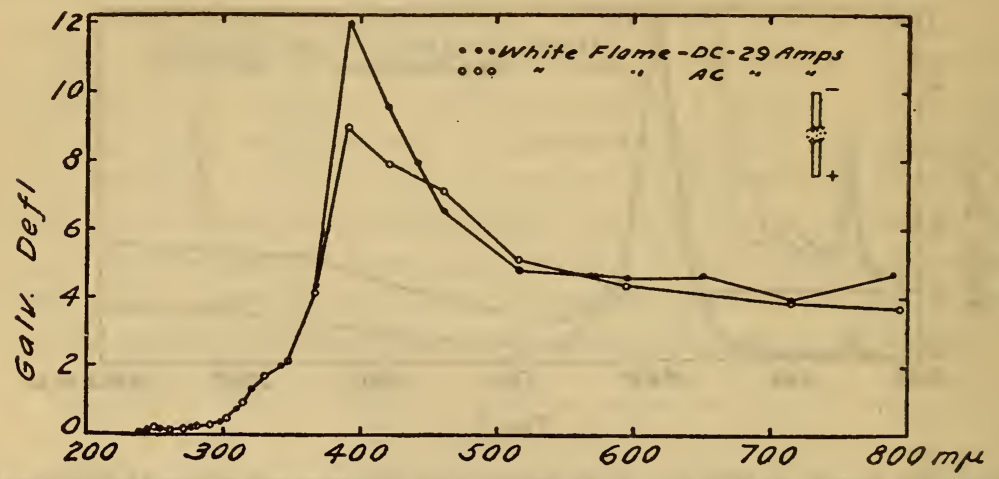

Fig. 11

On the left-hand side of Figure 17 is depicted the spectral energy distribution of the white-flame carbon arc on 29, 88, and 122 amperes, respectively.

The spectral-energy curves which were set to equal intensities in the region of $225 \mathrm{~m} \mu$ by applying suitable factors to the original observations do not superpose at $275 \mathrm{~m} \mu$; the one for 29 amperes being the

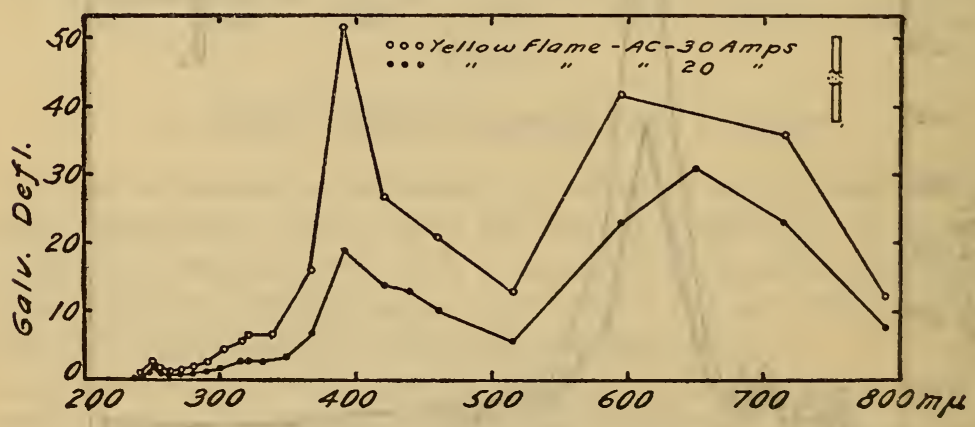

Fig. 12

highest, as is to be expected, if the intensity at $225 \mathrm{~m} \mu$ is relatirely less than on 122 amperes. As actually observed, the ratio of intensities at $350 \mathrm{~m} \mu$ was 6 as compared with the ratios of 12 to 15 at wave lengths of 235 to $225 \mathrm{~m} \mu$, showing the very marked increase in emission that is obtained in the extreme ultra-violet radiation from the high-intensity white-flame arc. 
In Figure 18 is shown the spectral-energy distribution of the radiation from a $12.7 \mathrm{~mm}$ white-flame vertical-trim carbon arc on 29 amperes, operated in a Macbeth holder which was provided with an aluminum-painted reflector. In this same illustration is given the spectral-energy distribution of an arc of a $12.7 \mathrm{~mm}$ white-flame positive and an "orotip" $11.6 \mathrm{~mm}$ neutral-core negative. Both electrodes were inclosed in a copper sheath to increase the electrical conductivity. This combination was operated as a rertical arc, on 90 amperes, in a Schwartz lamp which is provided with a white diffusing reflector. The spectral intensities of the 90 -amperes are were observed to be a little more than five times those of the 29amperes arc. With the exception of the high emission at $500 \mathrm{~m} \mu$ there is no marked difference in the relative spectral distribution between this combination on 90 amperes and the white-flame arc on 29 amperes. In fact, as shown in Figure 17, the relative spectral-

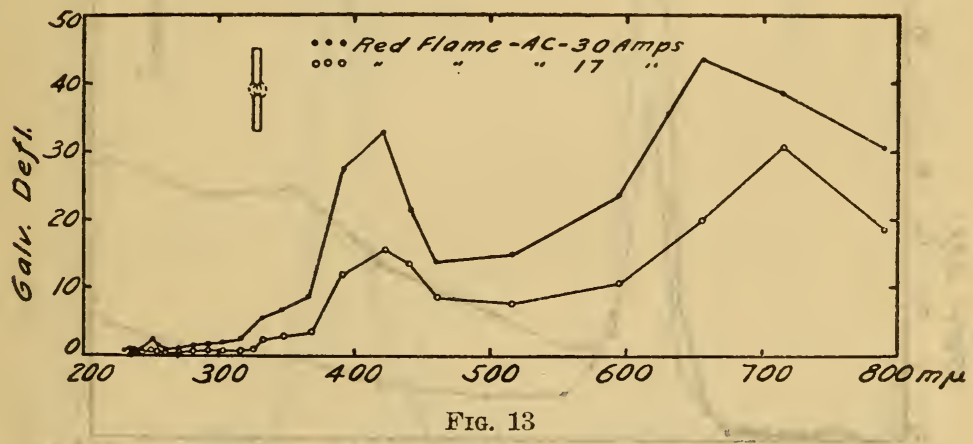

energy distribution of this combination is a closer match to that of the white-flame arc on 29 amperes than to the high-intensity white-flame arc on 88 amperes, excepting in the extreme ultraviolet where the relative intensities lie between the 29 and 88 amperes arcs.

A study of the data will disclose that the ultra-violet radiation component is a complex function of electrical current through, and the chemical composition of, the electrode. The high-powered installations will naturally be less common than lamps requiring 10 to 20 amperes. The data on the cobalt, nickel, and aluminum ares indicate how one can obtain a source rich in these extreme ultraviolet rays. The question of total intensity may be solved by using a burnished aluminum reflector which is quite nonselective in ultraviolet reflection and by operating at a closer distance. That the reflector is an important factor is shown in the measurements on the white-flame arc on 29 to 90 amperes, respectively, which differ 
but little in total intensity because in the former there was a reflector.

In concluding this part of the discussion it is relevant to repeat and emphasize the fact already mentioned, that the method of transmission screens measures all the radiation emanating from the arc, whereas the spectrometer analyses only that part of the central arc and the incandescent electrodes projected on the slit. Oftentimes the arc has a flame streaming out at the side and hence not projected on the spectrometer slit, but the radiation emanating from this "wing" is intercepted in the total radiation measurement.

The spectral component of wave lengths less than $290 \mathrm{~m} \mu$ being so small and the arc being so variable, when discrepancies arise it

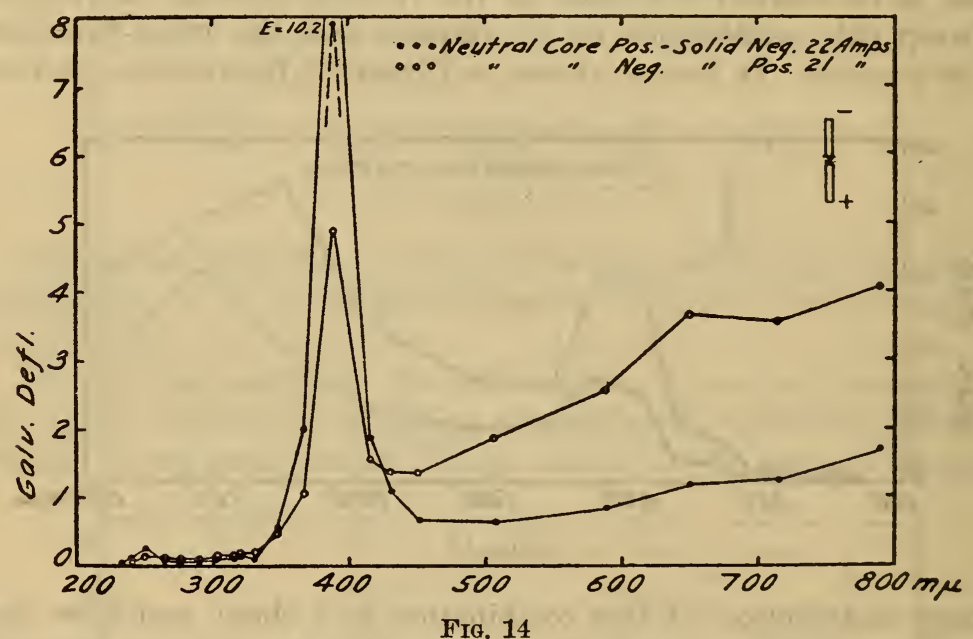

is best to consider the sum of all the components to $350 \mathrm{~m} \mu$, or even better, to $450 \mathrm{~m} \mu$.

\section{CONCLUDING REMARKS}

From the foregoing data it is evident that the radiation emitted by these various carbon electrodes is exceedingly complex. When the lamp is provided with a chimney or reflector which becomes heated, further complexities are introduced. The heat radiated by the globe or a metal hood has no counterpart in sunlight, and it may be uncomfortable to the patient. The operating distance from the patient is therefore a matter of trial and is not to be decided entirely by the radiometric measurements.

For example, in a certain type of carbon arc lamp inclosed by a chimney the radiant flux was found closely the same as that of the 
sun, in spectral composition and in intensity, at a distance of 1 foot from the arc. However, the heat from the glass globe surrounding the are was so intense that it was uncomfortable to the bare hand. But at a distance of 2 to 3 feet from the arc, and at an angle of $45^{\circ}$ below the horizontal plane through the arc (on direct current with the upper electrode positive; that is, the hotter) the exposed hand felt the warm comfortable glow experienced in sunlight.

The data on the carbon arc given in Table 2 are interesting in that the spectral component radiation of the very short ultra-violet rays 170 to $290 \mathrm{~m} \mu$ is only from 1 to 4 per cent of the total. When the arc

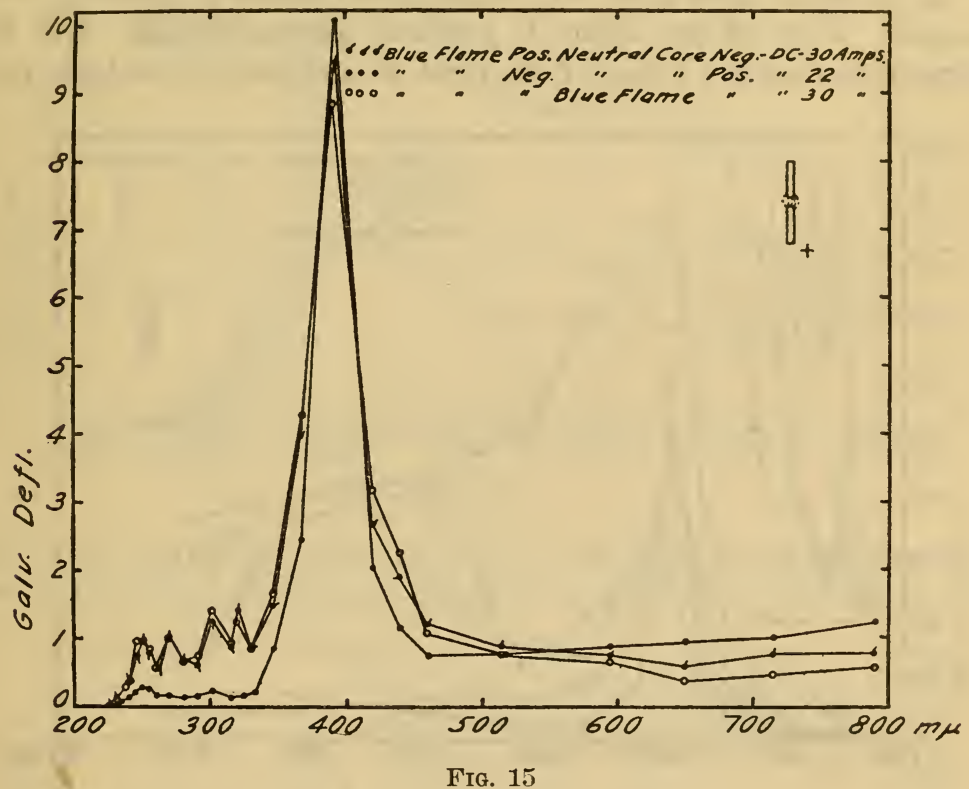

is inclosed in a quartz globe or is uninclosed, these shortest ware lengths are transmitted.

When the electrodes are inclosed in a glass globe, the ultra-violet component radiation of wave lengths 170 to $290 \mathrm{~m} \mu$ of the arc of pure carbon is eliminated and the component at 290 to $450 \mathrm{~m} \mu$ is close to that of sunlight.

The impregnated arc emits strongly in the visible spectrum, the amount so emitted depending upon the kind of salts used in the carbon electrodes. In these carbon ares the short ultra-violet rays at 290 to $310 \mathrm{~m} \mu$ are probably more intense than in sunlight where, as already stated, the intensity is less than one-millionth of that of the visible rays. 
In the foregoing pages data are given showing the great difference in the spectral component radiation of the sun, the carbon arc, and the mercury vapor are in a quartz burner.

The mercury arc is especially rich in the extremely short rays which have a rapid germicidal action. These rays are absorbed in extremely thin layers of the skin and, hence, can not penetrate very deep into the body. The longer rays, 400 to $1,400 \mathrm{~m} \mu$ have a greater penetration. Rays of still greater wave length, 4,000 to $7,000 \mathrm{~m} \mu$, such as obtained from a source at a temperature of 100 to $300^{\circ} \mathrm{C}$., can not penetrate deeply into the blood stream.

The action of these light rays on the blood stream is probably very complex. Part of the action is probably photochemical. But the supposition that the action of the light on one part of the body pro-

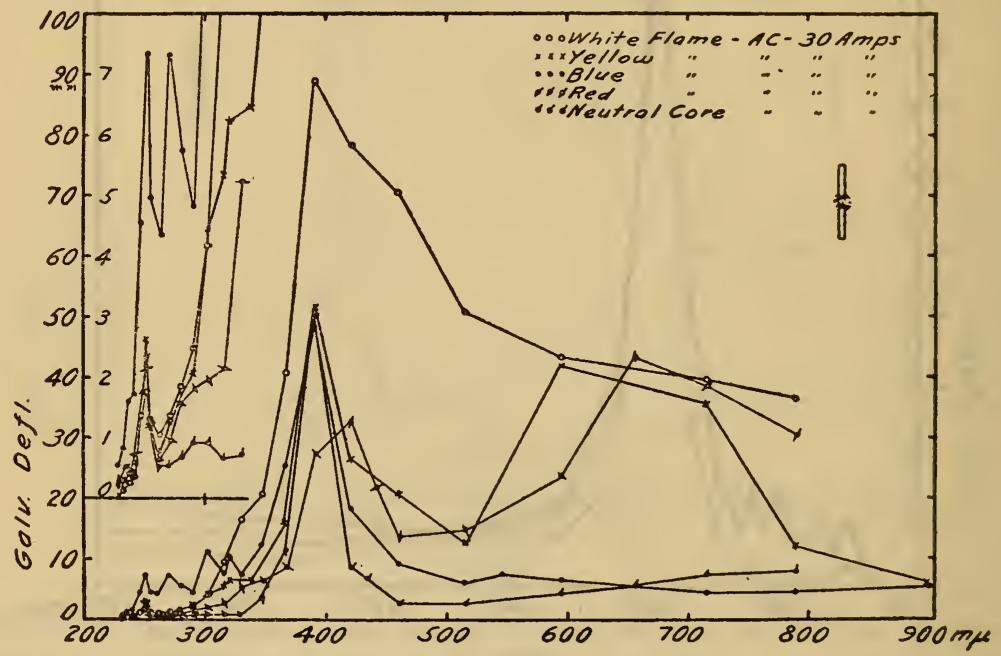

FIG. 16

duces a fluorescence in the blood stream which is carried to or produces a fluorescence deep within an unilluminated part of the body seems untenable, because fluorescence is a phenomenon that occurs only at the point where, and only so long as, the object is irradiated; and it ceases the moment the light stimulus is shut off. Hence, if a fluorescent substance which is introduced into the blood stream has a therapeutic effect it is more likely owing to some photochemical change in the material rather than owing to the fluorescent property of the material. Some other nonfluorescent material might produce the same effect, either by undergoing a photochemical change in combination with material in the blood stream or by some catalytic action on the white blood corpuscles. 
It seems quite possible for ultra-violet rays to produce fluorescence in the blood stream, say, in the white blood corpuscles, at the point

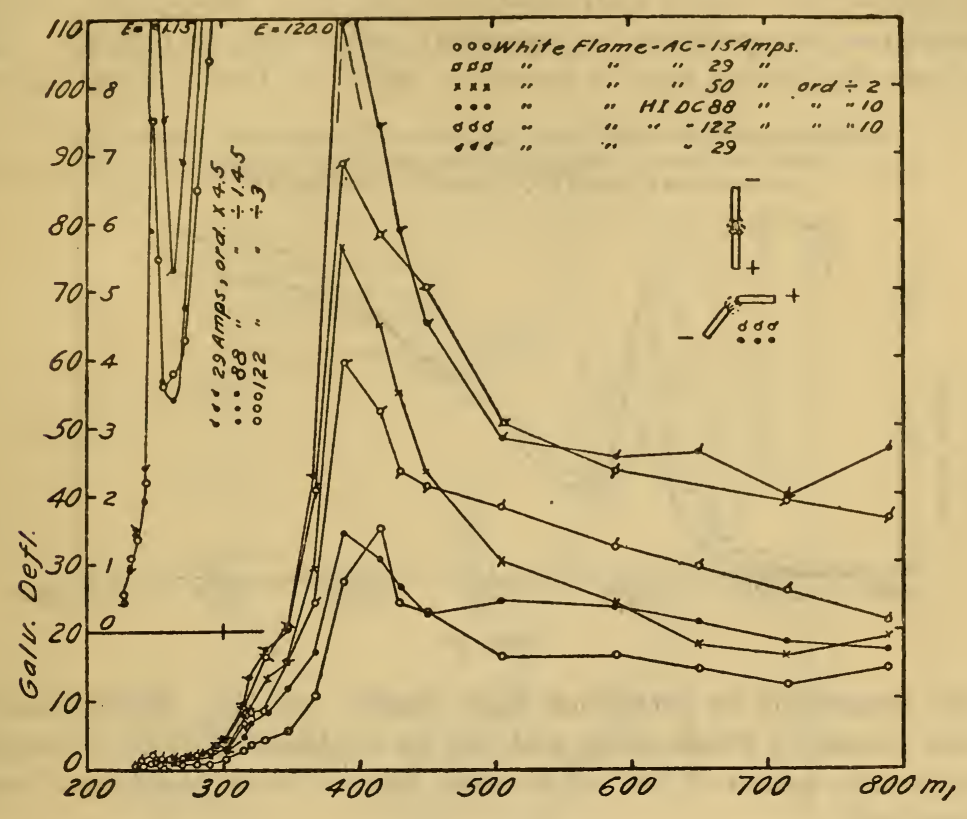

Fig. 17

where the rays impinge on the body. But this fluorescence would cease immediately after the corpuscle has passed from under the spot

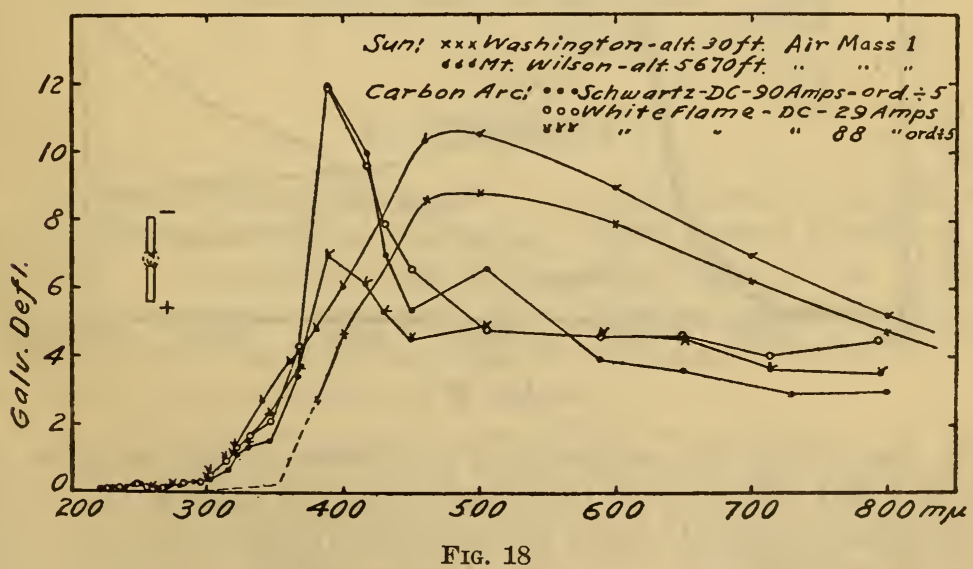

irradiated. Hence, it is more likely that the ultra-violet rays stimulate the white corpuscles to greater activity, which continues as they travel deeper into the body. 
While these short ultra-violet rays are destructive to protoplasm it has been observed that when the destructive action has not been carried too far there is a stimulation of the cell. The nature of this stimulation is a problem in physiology rather than in physics. The purpose in alluding to it is merely to point out that it seems physi-

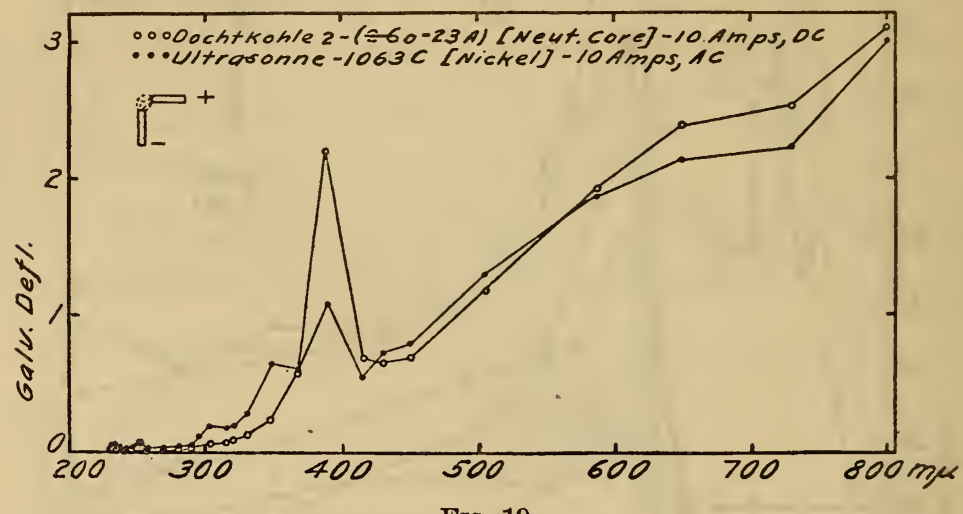

Frg. 19

cally impossible to introduce light deeply into the unilluminated blood stream by fluorescence, and that an explanation of the observed therapeutic action of the ultra-violet rays is to be sought on some other basis.

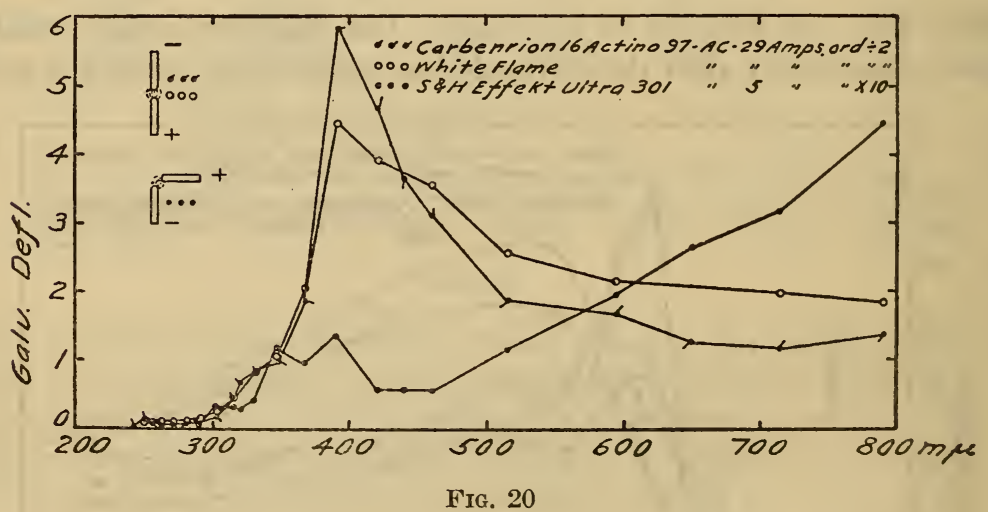

In concluding this discussion, it is relevant to call attention to the fact that differences in therapeutic action of sunlight and of the white-flame carbon arc light, which closely resembles sunlight, may arise from differences in temperature conditions surrounding the body. 
The increased beneficial effect observed at higher altitudes, where the ultra-violet solar rays of short wave length are more intense, raises the question whether an artificial source even richer than the sun, in the short wave lengths at 290 to $400 \mathrm{~m} \mu$ and emitting radiation closely similar to that of the sun in the visible and near infra-red spectrum, may not be even more beneficial than sunlight in the therapeutic treatment of certain diseases.

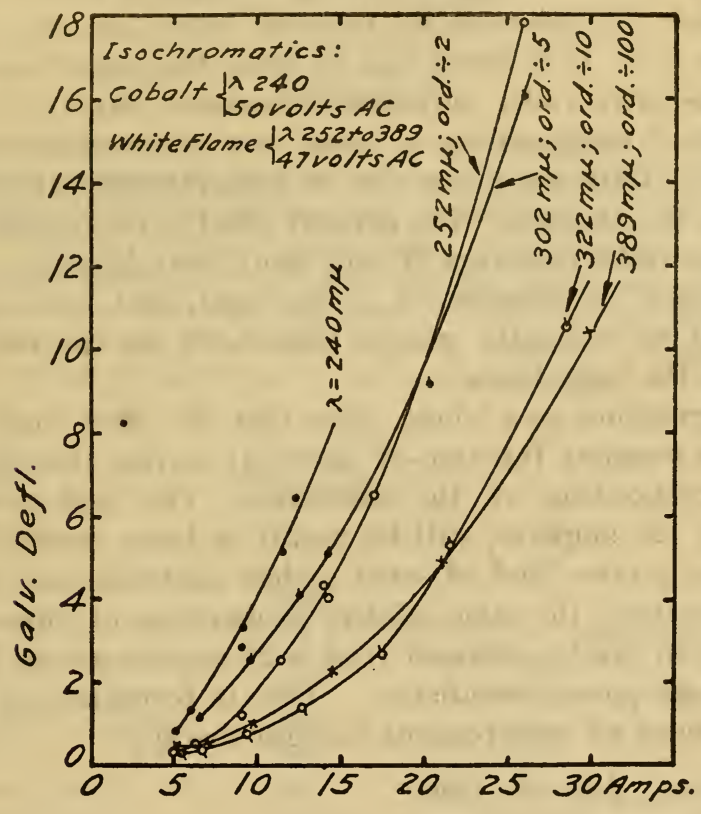

FIG. 21

\section{SUMMARY}

The object of the present paper is to present data on the spectral energy distribution of the carbon arc under various conditions of operation. Comparative data are presented also of the spectral energy distribution of the sun, of a 1,500-watt gas-filled tungsten lamp, the quartz mercury arc; also of the radiation emitted by the arc between rods of nickel and of tungsten.

Data on the carbon arc were obtained by two methods: (1) Spectral energy curves in the ultra-violet and the visible spectrum by means of a quartz spectroradiometer and (2) spectral radiation components in seven steps throughout the whole spectrum by means of transmission screens.

A study was made of various cored carbons, such as white flame, red flame, yellow flame, neutral core, nickel core, etc., to learn the 
effect of the core upon the spectral energy distribution. It was found that the intensity of the cyanogen band at $389 \mathrm{~m} \mu$, is affected (decreased) by the presence of strontium and nickel. The ultraviolet component radiation is greatly increased by the presence of nickel, cobalt, and aluminum. On the other hand, copper and tungsten do not appreciably increase the ultra-violet emission.

The effect of varying the electric current, also the effect of using d. c. and a. c., was investigated, and it was found that in some parts of the ultra-violet spectrum the emission bands are more intense on d. c. than on a. c. It is shown that by using the proper size of carbon electrode the ultra-violet radiation is increased twenty to fifty fold.

The effect of combinations of metal core and neutral core carbons was studied. Data are given also on high-intensity ares using currents up to 125 amperes. The general effect is to increase the emission of ultra-violet radiation of very short wave lengths.

The question of penetration is discussed, and it is shown that radiation of wave lengths greater than $1,400 \mathrm{~m} \mu$ can not penetrate deeply into the body tissue.

The observations, as a whole, show that the ultra-violet radiation emitted is a complex function of electrical current through, and the chemical composition of, the electrodes. The high-intensity arc, using 90 to 125 amperes, will be useful in large installations. By choosing the proper kind of cored carbon electrodes and the proper working distances, the same relative proportions of ultra-violet and total radiation can be obtained from a 20 -ampere arc as is obtained from the high-power installation. This is fortunate, as it will be possible to meet all requirements in light therapy.

Washington, July 30, 1926. 